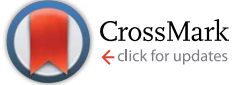

Cite this: J. Mater. Chem. A, 2016, 4, 13183

Received 23rd May 2016

Accepted 23rd July 2016

DOI: $10.1039 / c 6 t a 04273 b$

www.rsc.org/MaterialsA

\section{Combination of solid state NMR and DFT calculation to elucidate the state of sodium in hard carbon electrodes $\uparrow$}

\author{
Ryohei Morita, ${ }^{a}$ Kazuma Gotoh, ${ }^{\text {ab }}$ Mika Fukunishi, ${ }^{\text {bc }}$ Kei Kubota, ${ }^{\text {bc }}$ Shinichi Komaba, ${ }^{\text {bc }}$ \\ Naoto Nishimura, ${ }^{d}$ Takashi Yumura, ${ }^{d}$ Kenzo Deguchi, ${ }^{e}$ Shinobu Ohki, ${ }^{e}$ \\ Tadashi Shimizue and Hiroyuki Ishida ${ }^{a}$
}

\begin{abstract}
We examined the state of sodium electrochemically inserted in $\mathrm{HC}$ prepared at $700-2000{ }^{\circ} \mathrm{C}$ using solid state Na magic angle spinning (MAS) NMR and multiple quantum (MQ) MAS NMR. The ${ }^{23} \mathrm{Na}$ MAS NMR spectra of $\mathrm{Na}$-inserted $\mathrm{HC}$ samples showed signals only in the range between +30 and $-60 \mathrm{ppm}$. Each observed spectrum was ascribed to combinations of $\mathrm{Na}^{+}$ions from the electrolyte, reversible ionic $\mathrm{Na}$ components, irreversible $\mathrm{Na}$ components assigned to solid electrolyte interphase (SEI) or nonextractable sodium ions in $\mathrm{HC}$, and decomposed $\mathrm{Na}$ compounds such as $\mathrm{Na}_{2} \mathrm{CO}_{3}$. No quasi-metallic sodium component was observed to be dissimilar to the case of $\mathrm{Li}$ inserted in HC. MQMAS NMR implies that heat treatment of $\mathrm{HC}$ higher than $1600{ }^{\circ} \mathrm{C}$ decreases defect sites in the carbon structure. To elucidate the difference in cluster formation between $\mathrm{Na}$ and $\mathrm{Li}$ in $\mathrm{HC}$, the condensation mechanism and stability of $\mathrm{Na}$ and $\mathrm{Li}$ atoms on a carbon layer were also studied using DFT calculation. $\mathrm{Na}_{3}$ triangle clusters standing perpendicular to the carbon surface were obtained as a stable structure of $\mathrm{Na}$, whereas $\mathrm{Li}_{2}$ linear and $\mathrm{Li}_{4}$ square clusters, all with $\mathrm{Li}$ atoms being attached directly to the surface, were estimated by optimization. Models of $\mathrm{Na}$ and Li storage in $\mathrm{HC}$, based on the calculated cluster structures were proposed, which elucidate why the adequate heat treatment temperature of $\mathrm{HC}$ for high-capacity sodium storage is higher than the temperature for lithium storage.
\end{abstract}

\section{Introduction}

Secondary batteries are crucially important components, providing power for portable devices, transportation, and industries. As a representative secondary battery, lithium ion batteries (LIBs) are commonly used as indispensable energy storage systems for consumer electronics and vehicles because of their high working voltage, high energy density, good chargedischarge cyclability, and other benefits. Nevertheless, issues related to lithium resources and cost, are becoming increasingly

${ }^{a}$ Graduate School of Natural Science \& Technology, Okayama University, 3-1-1 Tsushima-naka, Okayama 700-8530,Japan.E-mail: kgotoh@okayama-u.ac.jp

${ }^{b}$ Elements Strategy Initiative for Catalysts and Batteries (ESICB), Kyoto University, Nishikyo-ku, Kyoto 615-8245, Japan

'Department of Applied Chemistry, Tokyo University of Science, 1-3 Kagurazaka, Shinjuku, Tokyo 162-8601, Japan

${ }^{d}$ Department of Chemistry and Materials Technology, Kyoto Institute of Technology, Matsugasaki, Sakyo-ku, Kyoto 606-8585, Japan

${ }^{e}$ National Institute for Materials Science, Tsukuba, Ibaraki 305-0003, Japan

$\dagger$ Electronic supplementary information (ESI) available: XRD patterns of HC samples, wide range ${ }^{23} \mathrm{Na}$ NMR spectra, Na NMR spectra of some inorganic sodium compounds and $\mathrm{NaPF}_{6} / \mathrm{PC}$ solutions, charge/discharge curves of reassembled cells, and DFT optimizations of an alkali atom ( $\mathrm{Li}$ or $\mathrm{Na}$ ) set at the center of $\mathrm{C}_{150} \mathrm{H}_{30}$. See DOI: 10.1039/c6ta04273b important with the increased demand for LIBs. Sodium insertion materials have attracted much attention as sodium ion batteries (NIBs), which might be an alternative to LIBs because of the abundant resources; sodium is the second-lightest and second-smallest alkali metal next to lithium, and has comparable electrode potential to that of LIBs. ${ }^{1-9}$ Several groups, including our group, have reported the excellent electrochemical performance of NIBs consisting of $\mathrm{Na}$ metal oxides and non-graphitazable carbon (hard carbon, HC) as positive electrodes ${ }^{10,11}$ and negative electrodes, respectively. ${ }^{12-16}$

For the development of NIBs possessing higher capacity, higher efficiency, long lifetime, and acceptable safety, it is indispensable to elucidate the states of the sodium ions and the mechanism of charging-discharging on the electrodes. We have investigated the state of sodium in an HC sample using solid state ${ }^{23} \mathrm{Na} \mathrm{NMR},{ }^{17}$ and have compared the state with lithium stored in HC. ${ }^{18-22}$ The behaviour of the sodium spectra appears to differ from that of lithium inserted in HC. ${ }^{7} \mathrm{Li}$ NMR signals in HC appear between 9 and 80-120 ppm. The chemical shift moves proportionally to the lithium content at ambient temperature, although ${ }^{23} \mathrm{Na}$ signals do not shift with the sodium content. The results suggest strongly that sodium quasimetallic clusters do not form in closed nanopores of HC, unlike lithium in HC, although sodium atoms occupy nano-sized 
pores, while the negative electrode is sodiated electrochemically. However, the HC sample inspected in the research was the only commercial product made from petroleum pitch, then optimized for practical use as an LIB negative electrode.

It has been reported that the optimum structure of $\mathrm{HC}$ for $\mathrm{Na}$ storage differs from that for Li storage. For example, Hasegawa et al. reported on the electrochemical performance of $\mathrm{HC}$ negative electrodes prepared from resorcinol-formaldehyde gels by heating at different temperatures. ${ }^{23}$ The reversible capacity beyond $300 \mathrm{~mA} \mathrm{~h} \mathrm{~g}{ }^{-1}$ was achieved for $\mathrm{Na}$ insertion into HC prepared by heat treatment between 1200 and $2000{ }^{\circ} \mathrm{C}$, although the highest reversible capacity of LIB was obtained generally for the $\mathrm{HC}$ heat-treated at about $1000-1200{ }^{\circ} \mathrm{C} .^{\mathbf{2 4 , 2 5}}$ The plateau region (under $0.1 \mathrm{~V}$ ) of the charge (desodiation) curves was enhanced at $1200-1600{ }^{\circ} \mathrm{C}$ for $\mathrm{Na}$, although that of delithiation decreased at those temperatures for Li. Simone et al. also reported electrochemical properties of $\mathrm{HC}$ derived from cellulose. ${ }^{26}$

This report describes the state analysis of sodium in $\mathrm{HC}$ prepared at various temperatures using solid state $\mathrm{Na}$ magic angle spinning (MAS) NMR and multiple quantum magic angle spinning (MQMAS) NMR. Particularly, we observe whether the quasi-metallic sodium clusters are formed or not in the $\mathrm{HC}$ created by a wide temperature range of $700-2000{ }^{\circ} \mathrm{C}$. One difficulty of evaluating the state of sodium in HC is its high reactivity in the atmosphere. Sodium metal and sodium-inserted HC react with tiny amounts of water, oxygen molecules, or vaporized electrolyte solvent more actively than lithium or lithium-inserted HC, even in sealed NMR sample rotors or an Ar-filled glove box. The high reactivity affected the Na NMR spectra and complicated the analysis, resulting in lower reproducibility. Therefore, for this study, we diligently observe timedependent variations of Na MAS NMR spectra. Then, we report the process of degradation of sodium ions in the samples. To elucidate the formation of $\mathrm{Li}$ and $\mathrm{Na}$ clusters in $\mathrm{HC}$, a condensation mechanism of $\mathrm{Li}$ and $\mathrm{Na}$ atoms on a carbon layer is studied using DFT calculation.

\section{Experimental}

\subsection{Preparation of Na-inserted HC samples and NMR measurement}

The HC samples were prepared from sucrose according to a previous report. ${ }^{27}$ Sucrose dehydrated at $180{ }^{\circ} \mathrm{C}$ for $48 \mathrm{~h}$ was milled substantially. Then it was heated at 700, 900, 1300, 1600, and $2000{ }^{\circ} \mathrm{C}$ for $1 \mathrm{~h}$ under inert gas flow to produce carbon samples of HC-700, HC-900, HC-1300, HC-1600, and HC-2000, respectively, which were characterized using powder X-ray diffraction (XRD) and BET surface area measurements. Na was inserted electrochemically into, and extracted from, each HC sample using a two-electrode 2032 coin cell. A working electrode made of each HC sample with PVDF binder (Kureha Chemical Inds.) ( $9: 1$ by weight) and a counter electrode of sodium metal (Kanto Chemical) were assembled with $1 \mathrm{M} \mathrm{NaPF}_{6} /$ propylene carbonate (PC, battery grade; Kishida Chemical) and fluoroethylene carbonate (FEC, 2 wt $\%$ ) as an additive. ${ }^{28}$ Chargedischarge profiles were collected by HJ1001-SD8 system
(Hokuto Denko). Insertion (sodiation) of $\mathrm{Na}$ was conducted at $25 \mathrm{~mA} \mathrm{~g}^{-1}$. For NMR measurements, each cell was cycled at least twice between 0 and $2.0 \mathrm{~V}$ ( vs. $\mathrm{Na} / \mathrm{Na}^{+}$) to ensure SEI formation on HC for acceptable passivation, then discharged (sodiated) to the specific state of charge (SOC). Subsequently, the cell was disassembled in an Ar-filled glove box to select HC samples. After rinsing gently with PC, each HC sample was sealed in a $3.2 \mathrm{~mm} \phi$ sample rotor for solid state NMR. We have confirmed that our rinsing procedure decreases only the intensity of $\mathrm{Na}$ electrolyte signals, and does not affect the shape of the other signals in the NMR spectra.

Using an NMR system (11.7 T magnet, DD2; Agilent Technologies Inc.) at a MAS frequency of $15 \mathrm{kHz},{ }^{23} \mathrm{Na}$ MAS NMR spectra of HC-700, HC-900, HC-1300, HC-1600, and HC-2000 samples were measured by accumulating 2000 scans. The ${ }^{23} \mathrm{Na}$ MQMAS NMR was performed using a 3QMAS pulse sequence on a spectrometer (ECA-500; JEOL) and an 11.7 T magnet at a MAS frequency of $20 \mathrm{kHz}$ for highly sodiated HC-1600 and HC-2000 samples. Each MQMAS spectrum was taken by an adjustment of the pulse condition using the 1D MAS experiment, and a subsequent accumulation over 3 days. $1 \mathrm{M} \mathrm{NaCl}$ aqueous solution was used as a reference at $0 \mathrm{ppm}$.

\subsection{DFT calculation}

For this study, density functional theory (DFT) calculations were performed with the B3LYP functional implemented in Gaussian 09 code to elucidate the state of sodium on a nanometer-sized carbon surface. We specifically examined how sodium atoms interact with a finite-sized $\mathrm{sp}^{2}$ carbon material as a model of the upper-most surface of HC. To obtain a finite-sized $\mathrm{sp}^{2}$ carbon material with a small HOMO-LUMO gap, we calculated the gap in the carbon cluster terminated by $\mathrm{H}$ atom with the $D_{6 \mathrm{~h}}$ symmetry (6.8 eV for $\mathrm{C}_{6} \mathrm{H}_{6}, 4.0 \mathrm{eV}$ for $\mathrm{C}_{24} \mathrm{H}_{12}, 2.83 \mathrm{eV}$ for $\mathrm{C}_{54} \mathrm{H}_{18}$, $2.12 \mathrm{eV}$ for $\mathrm{C}_{96} \mathrm{H}_{24}$, and $1.63 \mathrm{eV}$ for $\mathrm{C}_{150} \mathrm{H}_{30}$ ) using the $6-31 \mathrm{G}^{* *}$ basis sets for carbon and hydrogen atoms. Consequently, $\mathrm{C}_{150} \mathrm{H}_{30}$ was used as a model of a finite-size $\mathrm{sp}^{2}$ carbon material. DFT calculations optimized the state of sodium atoms on $\mathrm{C}_{150} \mathrm{H}_{30}$, where the numbers of sodium atoms were $1,7,13$, and 19. The $6-31 \mathrm{G}^{*}$ basis set was used for sodium atoms.

\section{Results and discussion}

\subsection{Characterization of HC samples}

All prepared samples (HC-700, HC-900, HC-1300, HC-1600, and HC-2000) showed typical powder XRD patterns as HC (Fig. S1 $\dagger$ ). The BET surface areas of the respective samples were 237,172 , $45,<1$, and $<1 \mathrm{~m}^{2} \mathrm{~g}^{-1}$, which also show a typical decrease as HC. Charge-discharge (desodiation-sodiation) curves of the cells, including HC samples prepared from sucrose in this study, and $\mathrm{Na}$ metal are presented in Fig. 1. The total charge (desodiation) capacity of the cell of $\mathrm{HC}-700$ is $193 \mathrm{~mA} \mathrm{~h} \mathrm{~g}^{-1}$. It increased concomitantly with increased heating temperature (Table 1). The highest capacity of $302 \mathrm{~mA} \mathrm{~h} \mathrm{~g}^{-1}$ was achieved for a HC1600 cell. At HC-2000, the desodiation capacity decreased considerably to $139 \mathrm{~mA} \mathrm{~h} \mathrm{~g}^{-1}$. Initial irreversible capacities of 98, 77, 66, 64, and $45 \mathrm{~mA} \mathrm{~h} \mathrm{~g}^{-1}$ were observed. They are 


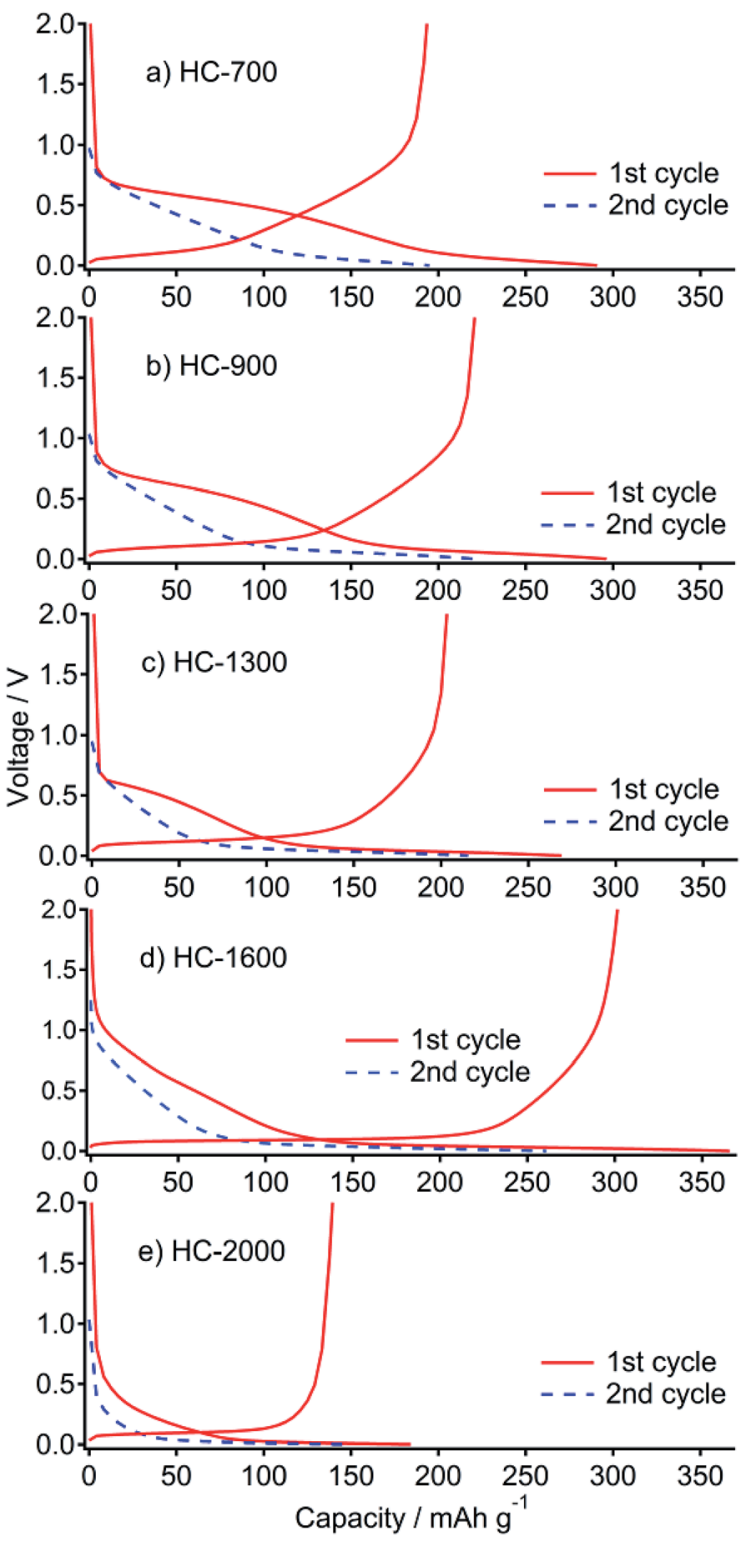

Fig. 1 First cycle and second sodiation of galvanostatic curve profiles for HC-700 (a), HC-900 (b), HC-1300 (c), HC-1600 (d) and HC-2000 (e) in $\mathrm{Na}$ cells at $25 \mathrm{~mA} \mathrm{~g}^{-1}$ between 0 and $2.0 \mathrm{~V}$.

ascribable to the decomposition of the electrolyte solution including solid electrolyte interphase (SEI) formation ${ }^{4,29}$ at 1.0$0.6 \mathrm{~V}$. The charge-discharge curves are divisible into two regions: (a) a slope region (above $0.1 \mathrm{~V}$ ) and (b) a plateau region (below $0.1 \mathrm{~V}$ ). Presumably, region (a) corresponds to the intercalation of $\mathrm{Na}$ into misaligned graphene layers, whereas (b) is explained by the insertion of Na into closed pores of HC. ${ }^{4,30}$ The capacity in region (a) decreased with carbonized temperature of HC (Table 1). However, the capacity at region (b) increased with carbonized temperature of $\mathrm{HC}$ until $1600{ }^{\circ} \mathrm{C}$, but it decreased from 1600 to $2000{ }^{\circ} \mathrm{C}$. It is noteworthy that the capacity of (a) also decreased by increasing the temperature from 1600 to $2000{ }^{\circ} \mathrm{C}$. That decrease is thought to be attributable to shrinkage of the interlayer distance between graphene layers in HC.

As described in the Introduction, Hasegawa et al. reported electrochemical performances of $\mathrm{HC}$ electrodes derived from the resorcinol-formaldehyde gel. ${ }^{23}$ The carbon shows high $\mathrm{Na}$ capacity over $300 \mathrm{~mA} \mathrm{~h} \mathrm{~g}{ }^{-1}$, even at temperatures higher than $2000{ }^{\circ} \mathrm{C}$, although our product shows smaller capacity in that temperature range. This is true because of their mutually different carbon structures, especially related to the micropores, which store Na. Their electrodes were cut from a carbon monolith and were used as-is, with no binder, for an electrode. The precursor structure might strongly affect the construction of carbon products.

\subsection{Na NMR of HC samples}

Fig. 2, 3, 4, 5 and 6, respectively, show ${ }^{23} \mathrm{Na}$ MAS NMR spectra of Na-doped HC-700, HC-900, HC-1300, HC-1600, and HC-2000. The wide range spectra of highly sodiated samples (between +1800 and $-300 \mathrm{ppm}$ ) are shown in Fig. S2 (see ESI $\dagger$ ). All samples show signals only in the range of +30 and $-60 \mathrm{ppm}$. Any shift of the peaks, depending on the state of charge (SOC) change, which had been observed in the ${ }^{7} \mathrm{Li}$ NMR spectra of $\mathrm{Li}$ in $\mathrm{HC}$, was not observed; the position of each peak was almost constant. No signal assigned to quasi-metallic sodium clusters between 1800 and $30 \mathrm{ppm}$ was observed in any HC samples. That result corresponds to results of our earlier study of a pitchbased standard HC product, ${ }^{17}$ and a very recent report by Johnson et al. $^{31}$ Each observed spectrum can be simulated by 24 Lorentzian components: (i) a narrow peak at about -9 and $-10 \mathrm{ppm}$, assignable to residual Na salt dissolved in electrolyte; (ii) a major broad component at about +5 to $-12 \mathrm{ppm}$, with more than 20 ppm of full width at half maximum (FWHM); (iii) a small peak near $+5 \mathrm{ppm}$; (iv) a very broad component around -15 to -25 ppm appeared only in HC-700.

Table 1 Sodiation capacities, desodiation capacities, and initial irreversible capacities of HC-700, HC-900, HC-1300, HC-1600, and HC-2000 samples obtained by electrochemical measurements

\begin{tabular}{|c|c|c|c|c|}
\hline \multirow[b]{2}{*}{ Sample } & \multicolumn{2}{|c|}{ Capacity (sodiation)/mA h g ${ }^{-1}$} & \multirow[b]{2}{*}{ Capacity (desodiation)/mA h g ${ }^{-1}$} & \multirow[b]{2}{*}{ Irreversible capacity/mA $\mathrm{h} \mathrm{g}^{-1}$} \\
\hline & Above $0.1 \mathrm{~V}$ & Below $0.1 \mathrm{~V}$ & & \\
\hline $\mathrm{HC}-700$ & 200 & 91 & 193 & 98 \\
\hline HC-900 & 171 & 125 & 221 & 77 \\
\hline HC-1300 & 113 & 156 & 203 & 66 \\
\hline HC-1600 & 129 & 237 & 302 & 64 \\
\hline HC-2000 & 62.5 & 121.5 & 139 & 45 \\
\hline
\end{tabular}




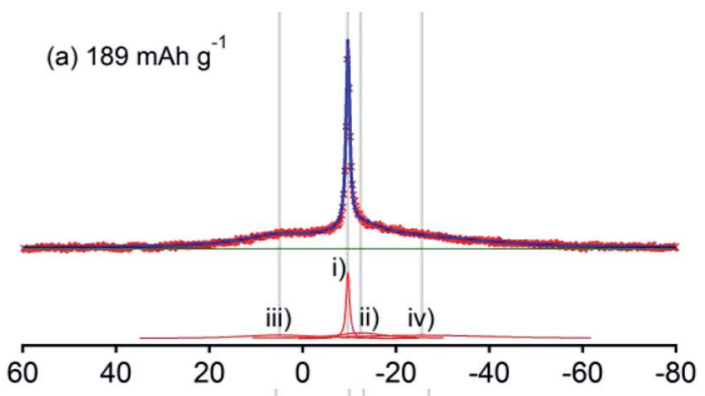

(b) $94 \mathrm{mAh} \mathrm{g}^{-1}$

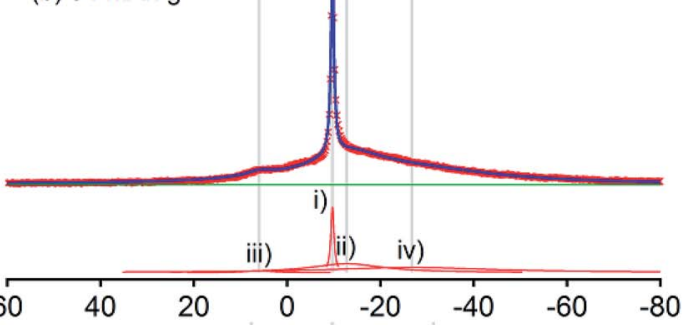

(c) $0 \mathrm{mAh} \mathrm{g}^{-1}$

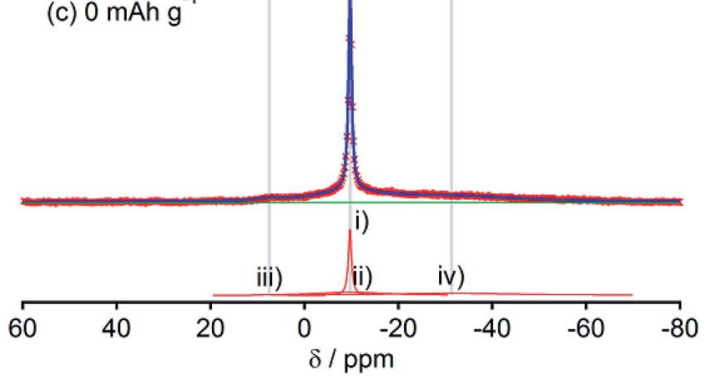

Fig. $2{ }^{23} \mathrm{Na}$ MAS NMR spectra of HC-700 samples (red $\times$ marks) at three sodiation levels. The fitting spectra and deconvoluted components of each spectrum are displayed by blue solid lines and red solid lines, respectively.

The component (iv) observed in HC-700 (Fig. 2), which seems to be an extension of the component (ii), can be ascribed to sodium inserted in the closed space of insufficiently carbonized HC. It disappeared in the other HC heat-treated at higher temperature. In samples HC-700 and HC-900 (Fig. 2 and 3), component (ii) having a peak at -5 to $-10 \mathrm{ppm}$ and a component (iii) at about $7 \mathrm{ppm}$, which is weaker than (ii), were detected. The components should be assigned to reversibly adsorbed sodium in HC because they almost disappeared in the spectra of completely desodiated carbon (Fig. 2(c) and 3(c)). The spectra of desodiated HC-700 and HC-900 showed only major signals of the electrolyte solution and an additional broad component around $-9 \mathrm{ppm}$, explained by ionic sodium compound contained in the solid electrolyte interphase (SEI) on the carbon surface, or non-extractable sodium ions in HC. Reports of previous studies by Alcántara et al. ${ }^{32}$ and our group ${ }^{17}$ described that the components (ii) and (iii) are ascribable to sodium stored in closed pores and in the space between misaligned graphene sheets, respectively. It is particularly interesting that sodium ions are apparently inserted into both adsorption sites simultaneously, whereas lithium is first stored between carbon layers and is then inserted into pores. ${ }^{33}$
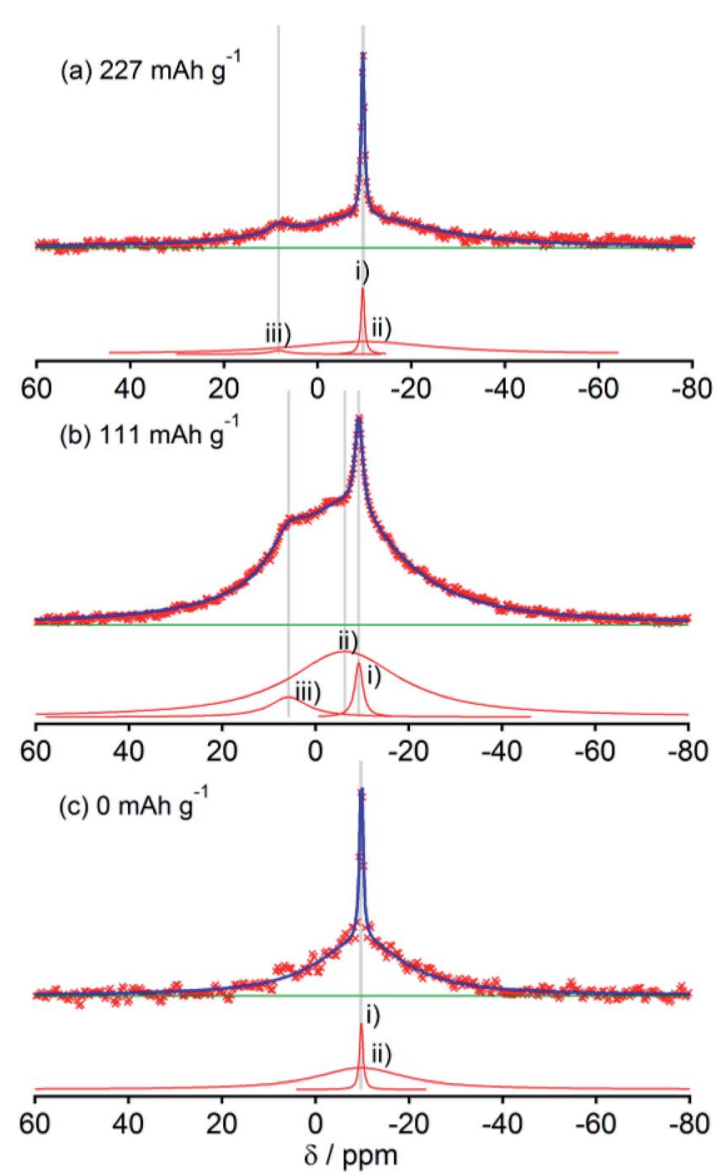

Fig. $3{ }^{23} \mathrm{Na}$ MAS NMR spectra of HC-900 samples (red $\times$ marks) at three different sodiation levels.

The spectral shapes of HC-1300 and HC-1600 are mutually similar (Fig. 4 and 5). Each spectrum was simulated by three components. The peaks and widths of component (i) and (ii) in HC-1300 and in HC-1600 are similar to those of HC-700 and HC900. Another small peak at 5-7 ppm in each spectrum of HC1300 and HC-1600 was also detected, which is narrower than component (iii) of HC-700 and HC-900. The peak is expected to be attributable to sodium compounds or ions formed irreversibly at HC electrodes because the peaks were observed even in desodiated ( $0 \mathrm{~mA} \mathrm{~h} \mathrm{~g}^{-1}$ ) samples (Fig. 4(c) and 5(c)). Components (iii) of HC-1300 and HC-1600 are explained by two overlapping sodium components: reversible and irreversible. Because of the smaller specific surface area of HC-1300 and HC$1600\left(<1 \mathrm{~m}^{2} \mathrm{~g}^{-1}\right)$, the irreversible component is more likely to be assigned to a decomposed sodium compound than SEI on the surface of HC. By comparison with ${ }^{23} \mathrm{Na}$ MAS NMR spectra of some sodium compounds (Fig. S3†), sodium carbonate $\left(\mathrm{Na}_{2} \mathrm{CO}_{3}\right)$, or hydrated sodium hydroxide $\left(\mathrm{NaOH}\left(\mathrm{H}_{2} \mathrm{O}\right)\right)^{34}$ correspond to the peak. Hydration of sodium is only slightly possible in nonaqueous battery electrodes. Therefore, the irreversible sodium compounds are assigned to sodium carbonate formed by the reaction of $\mathrm{Na}$ and oxidized sites on/in HC.

Although HC-2000 also showed components (i), (ii), and (iii) in the $138 \mathrm{~mA} \mathrm{~h} \mathrm{~g}^{-1}$ spectrum (Fig. 6(a)), the signal intensity of 


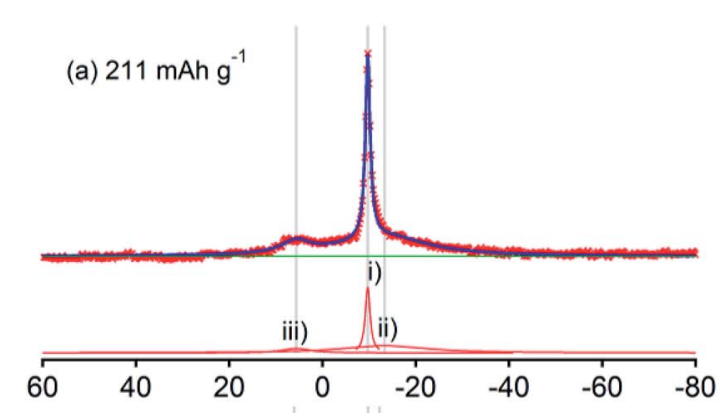

(b) $100 \mathrm{mAh} \mathrm{g}^{-1}$
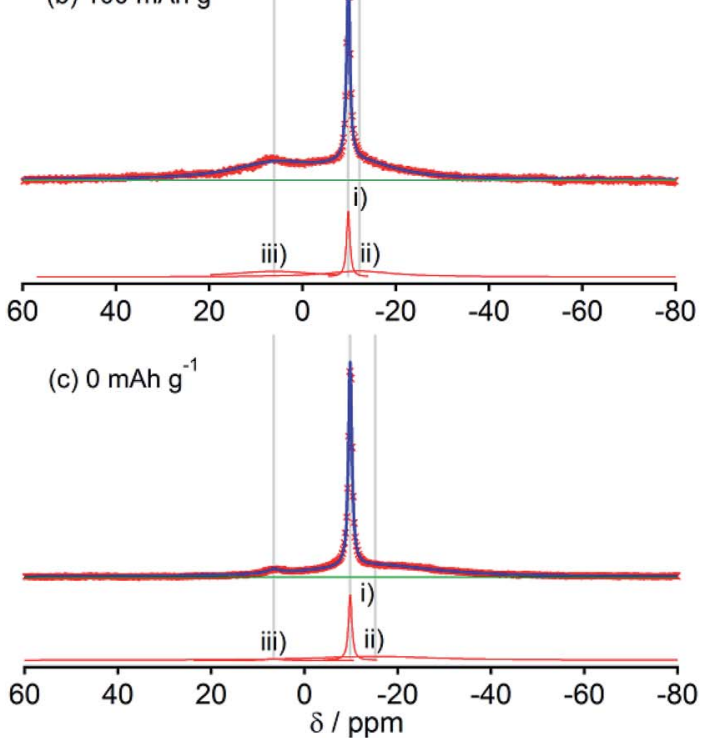

Fig. $4{ }^{23} \mathrm{Na}$ MAS NMR spectra of HC-1300 samples (red $\times$ marks) at three different sodiation levels.

(iii) was weak. It disappeared at $81 \mathrm{~mA} \mathrm{~h}^{-1}$. At the desodiated state $\left(0 \mathrm{~mA} \mathrm{~h} \mathrm{~g}{ }^{-1}\right)$, only signals of electrolyte solution and SEI were observed (Fig. 6(c)). Mutual differences of Na NMR spectra of HC-1600 and HC-2000 are discussed further in the following paragraphs, in light of the Na MQMAS NMR results.

The shapes of ${ }^{23} \mathrm{Na}$ NMR spectra in the present research (Fig. 2-6) differ from spectra of Na in a pitch-based HC product reported previously by our group. ${ }^{17} \mathrm{~A}$ major peak at $9 \mathrm{ppm}$ in pitch-based HC was altered to the broader component (iii); this might be attributable to the different structures of each HC, which originate from a different carbon source. In this study, we conducted the following two experiments to confirm our observation of sodium in "active" electrodes. (a) As the first experiment, fully sodiated HC-1300 cells after six cycles were disassembled in an Ar-filled glove box. Then the HC-1300 electrodes were rinsed using PC. Subsequently the cells were reassembled, and their electric capacities were measured. The charge-discharge curves of two representative reassembled HC1300 cells are shown in Fig. S4.† The reassembled cells showed 85-100\% capacities, compared with the original cells. (b) As the second experiment, the ${ }^{23} \mathrm{Na}$ NMR spectra of sodiated HC-1600 and HC-2000 samples were measured repeatedly 1 day and 2 days after the first measurement, shown in Fig. 5(a) and 6(a). As displayed in Fig. 7, sharp signals at -9 to $-10 \mathrm{ppm}$ of $\mathrm{Na}$ in
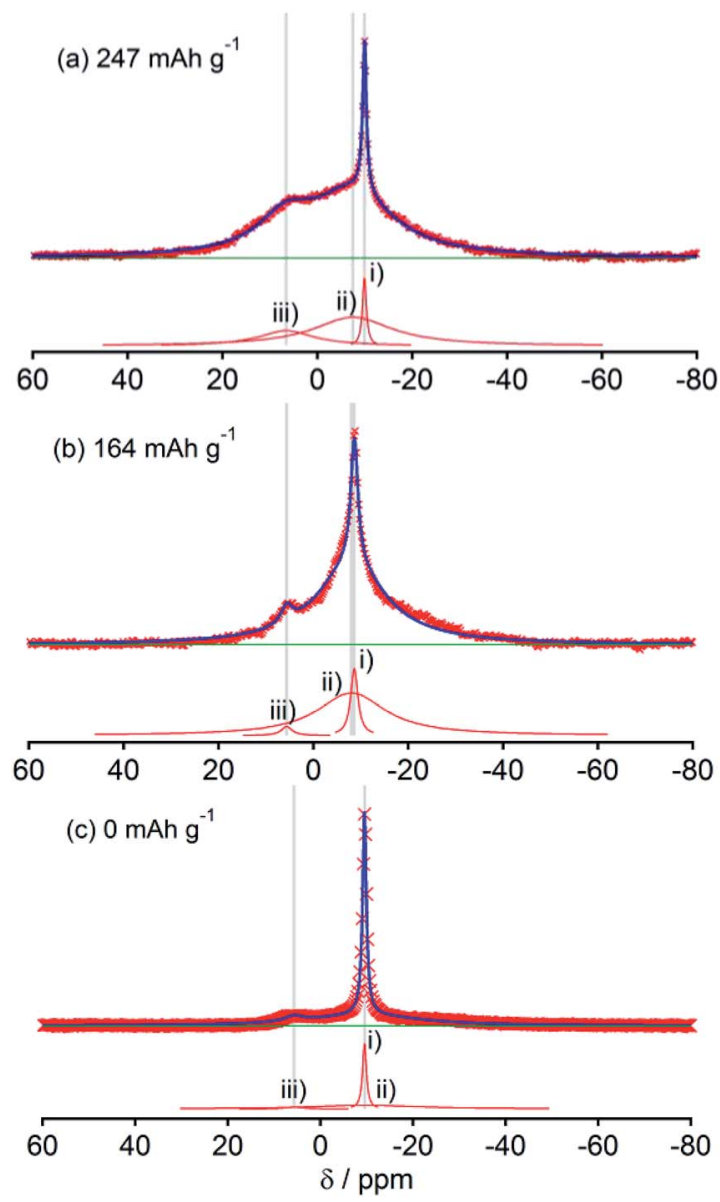

Fig. $5{ }^{23} \mathrm{Na}$ MAS NMR spectra of HC-1600 samples (red $\times$ marks) at three different sodiation levels.

electrolyte solution transformed the border and shifted to a higher frequency (about $-6 \mathrm{ppm}$ ). In addition, the broad (ii) component decreased gradually. Also, a new peak at $+5 \mathrm{ppm}$ assigned to $\mathrm{Na}_{2} \mathrm{CO}_{3}$ and/or $\mathrm{NaOH}\left(\mathrm{H}_{2} \mathrm{O}\right.$ ) (Fig. S3 $\dagger$ ) appeared and increased. The peak shift of $\mathrm{NaPF}_{6} / \mathrm{PC}$ solutions in $\mathrm{Na} \mathrm{NMR}$ increased concomitantly with decreasing concentration of $\mathrm{NaPF}_{6}$, as shown in Fig. S5. $\uparrow$ Therefore, Na ions in electrolyte solution seemed to decrease over a few days by reactions on the HC surface and the formation of solid Na compounds in an NMR sample rotor. The reversible component of (iii) 1D spectrum (Fig. 5(a)) might move, but it was involved in the major broad component of the spectrum from 2 days after (bottom spectrum of Fig. 7(a)). According to the experiments presented in Fig. 7(a) and (b), it is certain that our experiments have revealed the characteristics of the active (not decomposed) and fresh state of sodium in HC electrodes.

${ }^{23} \mathrm{Na}$ MQMAS (3QMAS) NMR spectra of sodiated HC-1600 and HC-2000 are presented in Fig. 8(a) and (b). In MQMAS NMR, a $2 \mathrm{D}$ spectrum with a horizontal $F_{2}$ axis and a vertical $F_{1}$ axis is acquired. The $1 \mathrm{D}$ spectrum projected to the $F_{2}$ axis corresponds to general MAS NMR, whereas the spectrum projected to the $F_{1}$ axis represents an isotropic spectrum, for which the quadrupolar effect is averaged. ${ }^{35}$ In fact, the projections of the $F_{2}$ axes in Fig. 8(a) and (b) don't coincide 

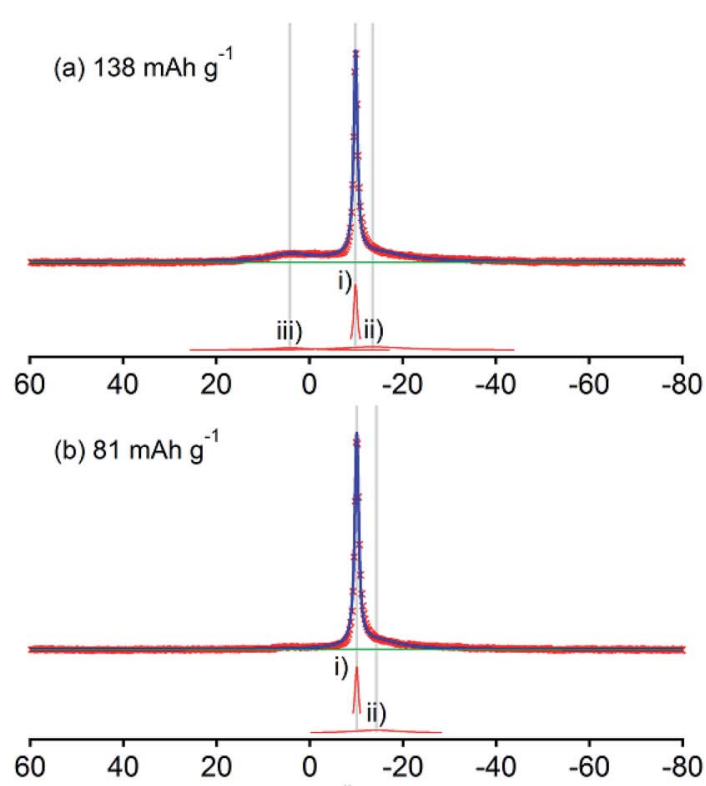

(c) $0 \mathrm{mAh} \mathrm{g}^{-1}$

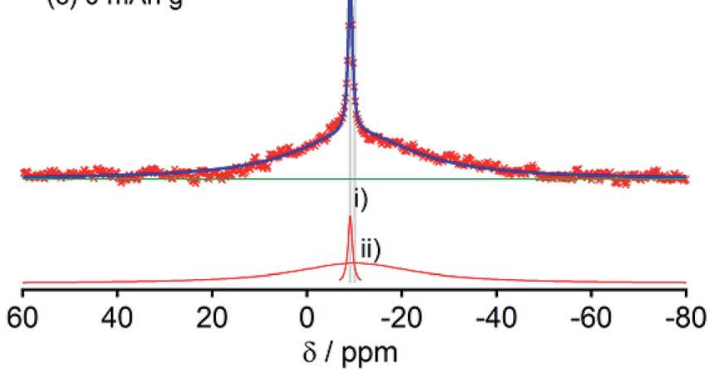

Fig. $6{ }^{23} \mathrm{Na}$ MAS NMR spectra of HC-2000 samples (red $\times$ marks) at three different sodiation levels.

with the initial state of the 1D spectra (Fig. 7(a) and (b)). Since a few hours were needed to adjust the condition of MQMAS pulse sequences for each measurement, the initial states of the MQMAS acquisition don't correspond to the 1D spectra. Furthermore, the MQMAS NMR spectra shown in this study might contain some decomposed components, as shown in the spectra in Fig. 7, because they were taken by accumulation over three days, as described in the Experimental section. Nevertheless, the results are useful because they can still distinguish active sodium components in HC. The 2D spectrum of HC-1600 (Fig. 8(a)) consists of two regions: a broad component $(\alpha)$ spreading from -17 to $0 \mathrm{ppm}$ in $F_{2}$ and +10 to $-5 \mathrm{ppm}$ in $F_{1}$, and a weaker component $(\beta)$ at around $5 \mathrm{ppm}$ in $F_{2}$, which roughly corresponds to the 1 D spectrum obtained 2 days after (bottom spectrum of Fig. 7(a)). The component $(\alpha)$ should be assigned to sodium in HC and in the deteriorated electrolyte solution. The latter component $(\beta)$ in the $2 \mathrm{D}$ spectra is located on the CS axis, with no extension along the $F_{2}$ axis. Therefore, it is ascribable to amorphous (non-crystallized) $\mathrm{Na}_{2} \mathrm{CO}_{3}$ and/or $\mathrm{NaOH}\left(\mathrm{H}_{2} \mathrm{O}\right)$ reduced during 3 days of accumulation to acquire the 2D MQMAS spectrum. The former component $(\alpha)\left(-17-0 \mathrm{ppm}\right.$ of $\left.F_{2}\right)$ includes some different components such as high crystallinity peaks extending along the $F_{2}$ axis and non-crystallized isotropic peaks. The $F_{1^{-}}$
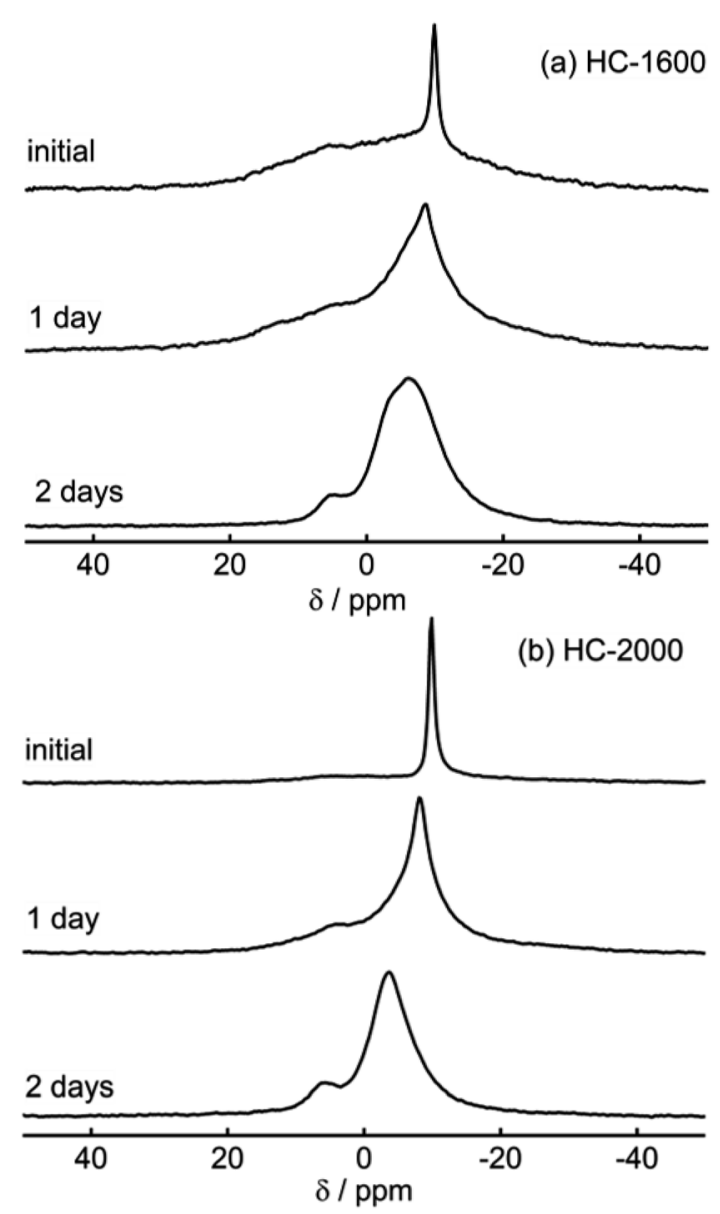

Fig. 7 Temporal variations of ${ }^{23} \mathrm{Na}$ MAS NMR spectra of sodiated HC1600 (a) and sodiated HC-2000 (b).

projected spectra of component $(\alpha)$ include at least three peaks. One of them could be a deteriorated electrolyte solution. Therefore, two (or more) peaks are explained by signals of Na stored in a carbon structure.

In contrast, the MQMAS spectrum of HC-2000 (Fig. 8(b)) showed different features. The $2 \mathrm{D}$ spectrum seems to include three components: an isotropic component along the CS axis, assignable to the deteriorated (or partially extracted) sodium from electrolyte solution, a high crystallinity peak between 0 and $-10 \mathrm{ppm}$ along the $F_{2}$ axis, explained by sodium in carbon, and a small component at $6 \mathrm{ppm}$ on the $F_{2}$ axis, attributed to decomposed $\mathrm{Na}_{2} \mathrm{CO}_{3}$ or $\mathrm{NaOH}\left(\mathrm{H}_{2} \mathrm{O}\right)$. Furthermore, the $F_{1}$-projected (isotropic) spectrum showed only one peak at $3 \mathrm{ppm}$. The results strongly suggest that the number of $\mathrm{Na}$ components in the carbon structure of HC-2000 is fewer than that of HC-1600. The main component of sodium in HC-2000 extends along the CS axis, which is assignable to disordered (i.e., amorphous) sodium. It can be concluded that a difference in carbon structure between HC-1600 and HC-2000 gave rise to a drastic difference in the manner of sodium storage, whereas little change was found for lithium storage, ${ }^{25}$ although the specific surface areas of both HC-1600 and HC-2000 are less than $1 \mathrm{~m}^{2} \mathrm{~g}^{-1}$. 

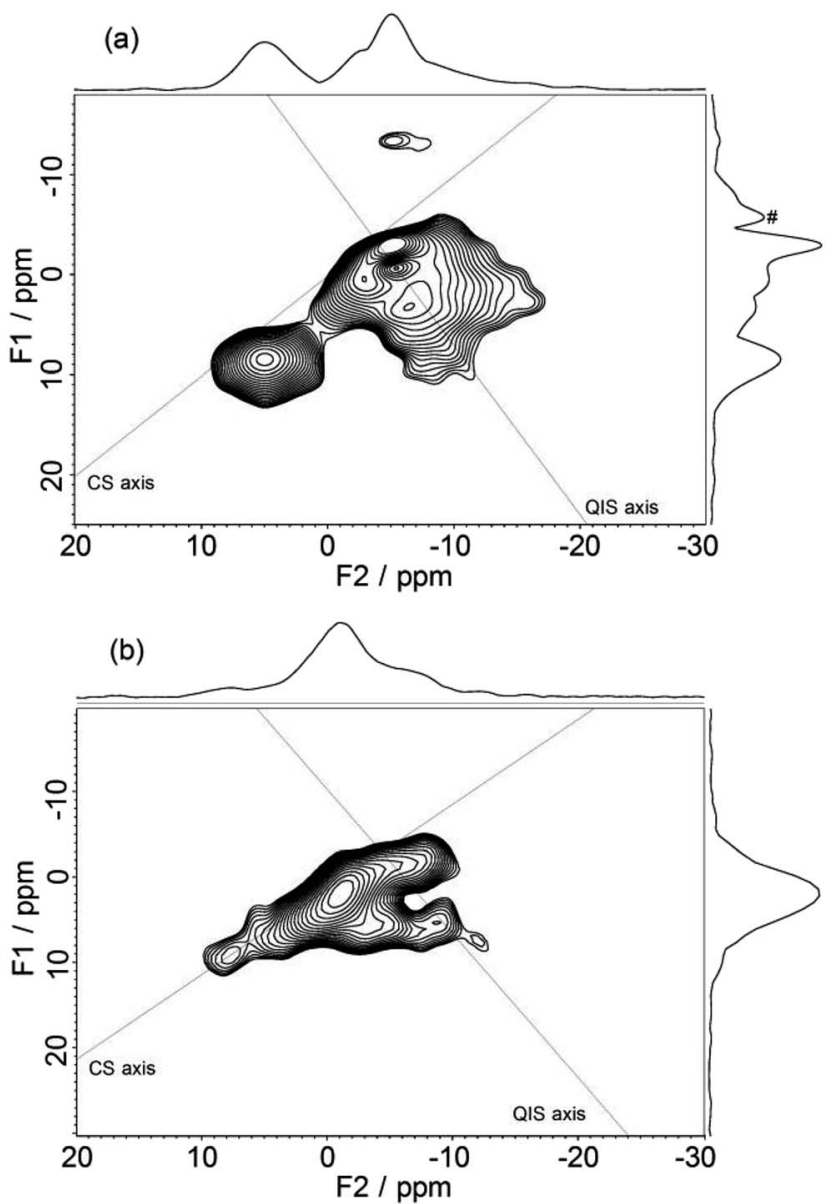

Fig. $8{ }^{23} \mathrm{Na}$ 3QMAS NMR spectra of sodiated HC-1600 (a) and sodiated $\mathrm{HC}-2000$ (b). A peak labelled by \# on a projection spectrum along $F_{1}$ is a $t_{1}$ noise (artifact).

\subsection{DFT computation results for the state of alkali atoms on $\mathrm{C}_{150} \mathrm{H}_{30}$}

Tsai et al. reported an ab initio calculation study of the model for disordered carbon. ${ }^{36}$ Their results clarified that large interlayer distances are favourable for $\mathrm{Na}$ ion intercalation into carbon layers, and that vacancy defects can greatly enhance the Na ion intercalation. Datta et al. ${ }^{37}$ and Xu et al. ${ }^{38}$ discussed the stability of $\mathrm{Na}$ on defective graphene and graphyne (graphdiyne), respectively. Kaur et al. reported a $\mathrm{Na}_{2}$ dimer structure on graphene. ${ }^{39}$ Also, the structure of alkali metal (Li, Na, K) - graphite intercalation compounds (GICs) have been studied computationally. ${ }^{\mathbf{4 0 - 4 2}}$ However, no information has been obtained for the condensation of $\mathrm{Li}$ or $\mathrm{Na}$ in the closed pores of $\mathrm{HC}$. To elucidate the state of sodium atoms on HCs, we performed density functional theory (DFT) optimization of some sodium atoms on $\mathrm{C}_{150} \mathrm{H}_{30}$ as a model of the upper carbon surface of HCs. For comparison, optimized geometries for corresponding lithium cases were obtained. When an alkali atom was set at the centre of $\mathrm{C}_{150} \mathrm{H}_{30}$, DFT optimizations placed the single $\mathrm{Li}(\mathrm{Na})$ atom separated from the centre by 1.77 (2.26) Å, as shown in Fig. S6. $\dagger$ According to Mulliken population analyses, the attached Li and $\mathrm{Na}$ atoms, respectively, have $+0.5 e$ and $+0.7 e$. The results demonstrate that cation $-\pi$ interactions stabilize the optimized structures in Fig. S6. $\dagger$ Actually, the optimized structure for the single lithium (sodium) case lies 18.1 (6.1) $\mathrm{kcal} \mathrm{mol}^{-1}$ below the dissociation limit toward the single atom and $\mathrm{C}_{150} \mathrm{H}_{30}$. Using the optimum separation between the alkali atom and $\mathrm{C}_{150} \mathrm{H}_{30}$, initial geometries for some alkali atoms on $\mathrm{C}_{150} \mathrm{H}_{30}$ were constructed, as shown in Fig. 9-11. The numbers of attached sodium atoms were regarded as 7 (Fig. 9), 13 (Fig. 10), and 19 (Fig. 11).

B3LYP/6-31G** optimizations of the initial geometries yielded local minima, as portrayed in Fig. 9-11. Striking differences are apparent between the optimized geometries of the lithium and sodium cases. In the optimized geometries for 13 or 19 lithium atoms on $\mathrm{C}_{150} \mathrm{H}_{30}$, small even-numbered clusters mainly exist, for which all lithium atoms, except one, are bound directly to the carbon surface. Actually, five $\mathrm{Li}_{2}$ clusters are apparent in the 13 lithium-atom case, and three $\mathrm{Li}_{4}$ clusters in the 19 lithium-atom case (Fig. 10). When the attached lithium atoms are fewer (i.e. the 7 lithium-atom case), single Li species sit independently on the carbon surface (Fig. 9). In contrast to the formation of even-numbered lithium clusters on $\mathrm{C}_{150} \mathrm{H}_{30}$, optimized geometries for the sodium cases mainly have threeatom $\left(\mathrm{Na}_{3}\right)$ clusters, plus one larger cluster (Fig. 10 and 11), except for the 7-sodium atom case in which $\mathrm{Na}_{2}$ clusters, corresponding to the dimer structure, ${ }^{39}$ were obtained (Fig. 9).

We found from Fig. 9-11 another characteristic difference in terms of how alkali atoms bind to the $\mathrm{sp}^{2}$ carbon surface. All lithium atoms, except one in Fig. 11(ii), are attached directly to the surface, with separations of around 2.0 ̊. In contrast, parts of the sodium atoms cannot be bound directly to the surface, instead they interact with other sodium atoms attached to the surface. The sodium atoms that are not directly bonded to carbon are separated from the carbon surface by approximately $5.4 \AA$ A. The different binding fashions determine the amounts of charge transfer. Actually, atoms that are bound directly to the carbon surface have positive charges, whereas other atoms have negative charges, according to Mulliken population analyses (shown in Fig. 10(iii) and 11(iii)), which might explain the negative chemical shifts of Na NMR signals ascribed to sodium in HC pores (component (ii) in the Na NMR spectra). Furthermore, the alkali cluster formation diminishes positive charges on atoms that are estimated from their singlet atoms. Results show that the attached $\mathrm{Li}_{2}$ and $\mathrm{Li}_{4}$ clusters are, respectively, $+0.2 e$ and $+0.5 e$. Similarly, the formed $\mathrm{Na}_{3}$ clusters have $+0.5 e$ in the sodium cases.

${ }^{23} \mathrm{Na}$ NMR chemical shifts of atoms in the $\mathrm{Na}_{3}$ clusters were estimated using the B3LYP/6-31G** function. A structure for a $\mathrm{Na}_{3}$ cluster on $\mathrm{C}_{150} \mathrm{H}_{30}$ was constructed by removing $16 \mathrm{Na}$ atoms from Fig. 11(iii), and the NMR shifts were calculated based on the gauge-independent atomic orbital (GIAO) method. The two Na atoms bonding to a carbon layer showed peak shifts between -2 and +30 ppm, whereas the chemical shift of the $\mathrm{Na}$ atom that is not directly bonded to carbon was estimated to be $c a$. -21 ppm (Fig. S7 $\dagger$ ). The estimated chemical shift values roughly correspond to the broad component (ii) of the ${ }^{23} \mathrm{Na}$ NMR spectra, which is ascribed to $\mathrm{Na}$ in the pores of carbon. Although the assignment of component (ii) and (iii) was firstly suggested by Alcántara 


\section{7 alkali atoms on $\mathrm{C}_{150} \mathrm{H}_{30}$}

(i) initial configuration

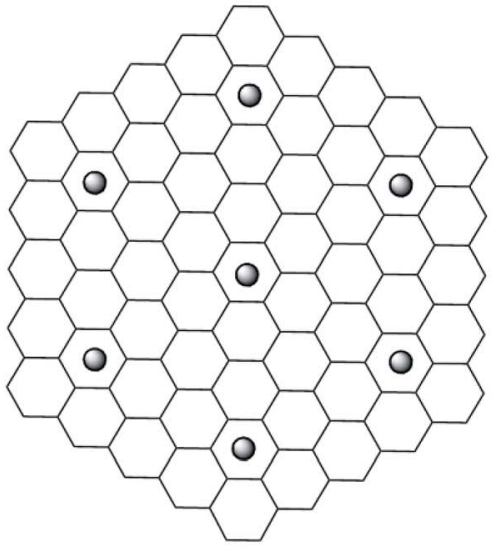

(ii) optimized geometry (Li case)

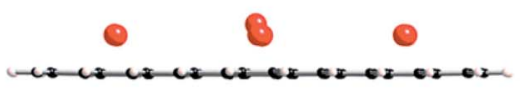

(iii) optimized geometry (Na case)

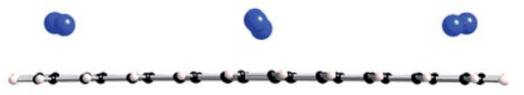

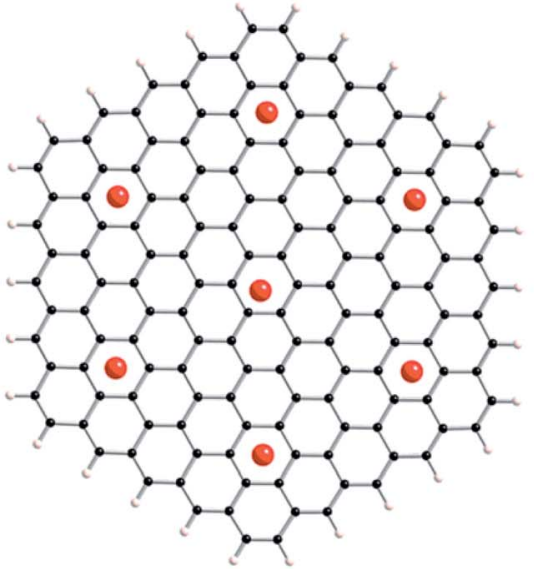

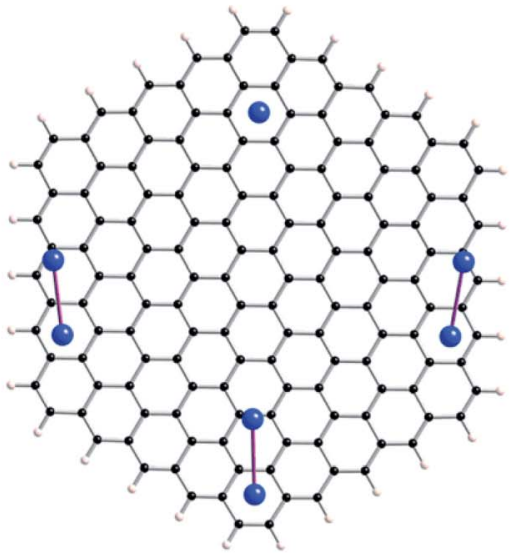

Fig. 9 Initial configuration of seven alkali atoms on a $\mathrm{C}_{150} \mathrm{H}_{30}$ plane (i), and its optimized geometry for lithium (ii) and sodium (iii).

\section{3 alkali atoms on $\mathrm{C}_{150} \mathrm{H}_{30}$}

(i) initial configuration (ii) optimized geometry (Li case)
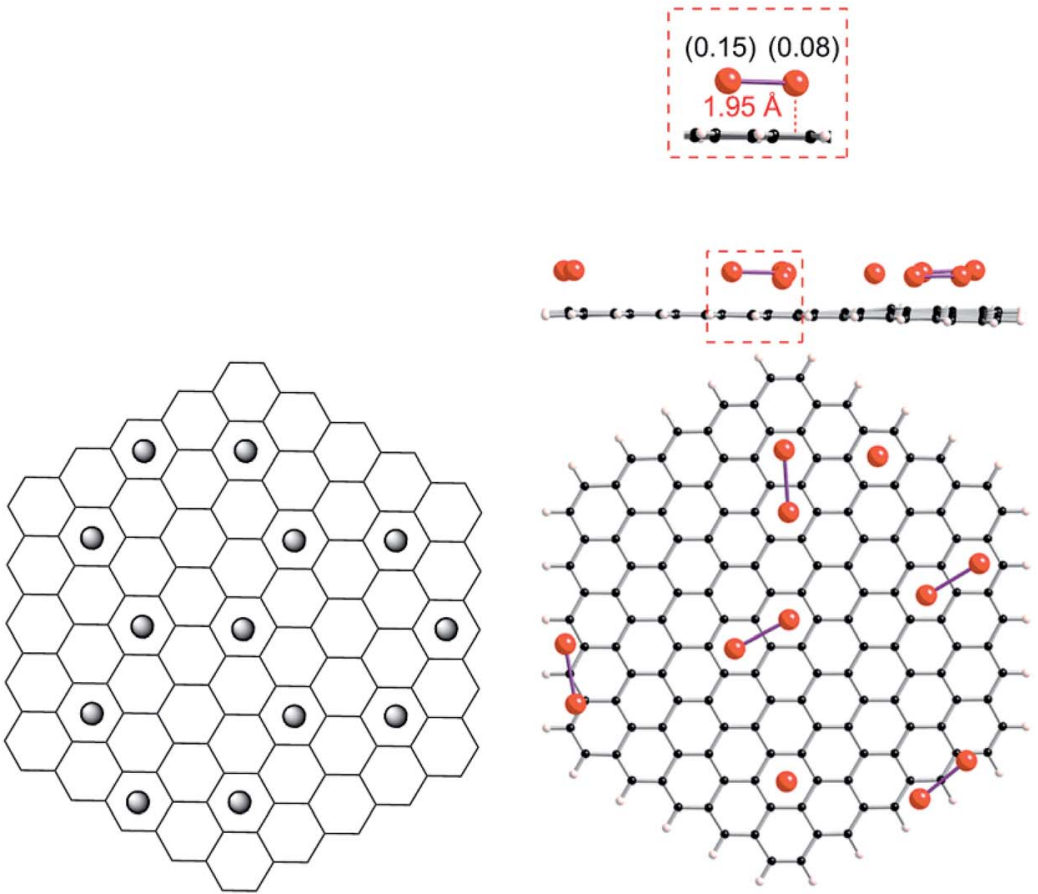

(iii) optimized geometry (Na case)
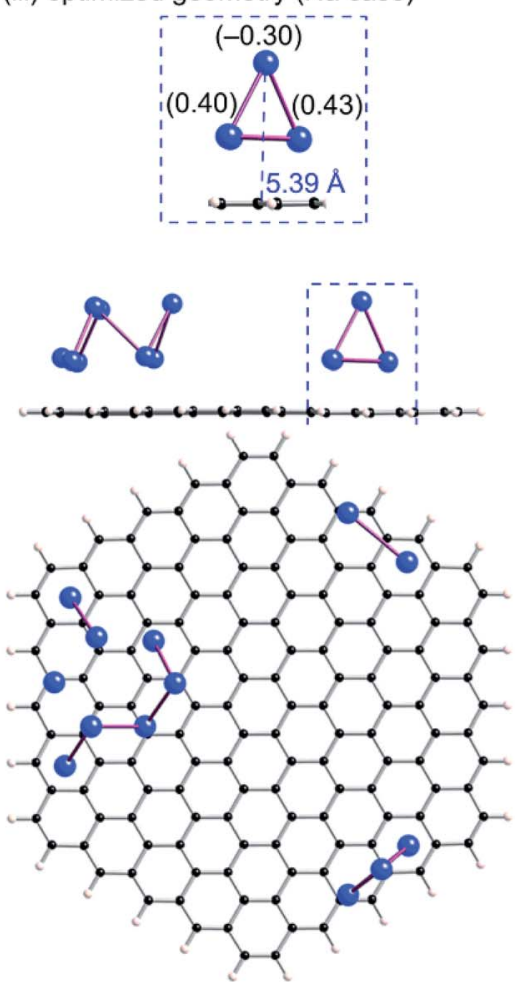

Fig. 10 Initial configuration of thirteen alkali atoms on a $\mathrm{C}_{150} \mathrm{H}_{30}$ plane (i), and its optimized geometry for lithium (ii) and sodium (iii). $\mathrm{Li}_{2} \mathrm{clusters} \mathrm{in}$ (ii) and $\mathrm{Na}_{3}$ clusters in (iii) are formed on the plane.

et al. ${ }^{32}$ no evidence has been reported. To the best of our knowledge, our $\mathrm{Na}_{3}$ triangle cluster model and the estimation of the NMR shift is the first explanation of the assignment.
The computational results presented above are helpful to understanding the ${ }^{23} \mathrm{Na}$ NMR results. Our DFT optimizations revealed that 13 or 19 sodium atoms on $\mathrm{C}_{150} \mathrm{H}_{30}$ aggregated to form triangle clusters, in addition to large clusters. These 
19 alkali atoms on $\mathrm{C}_{150} \mathrm{H}_{30}$

(i) initial configuration

(ii) optimized geometry (Li case)

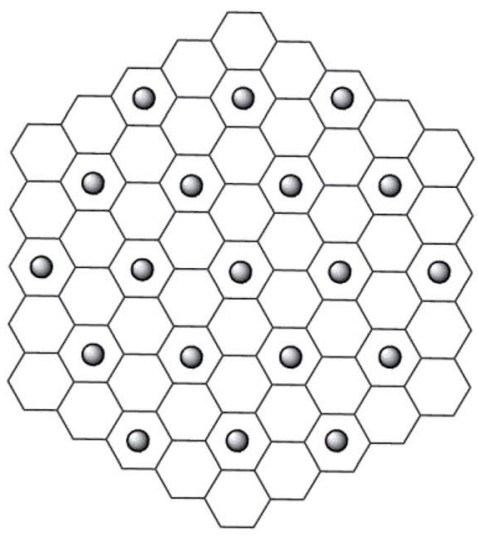

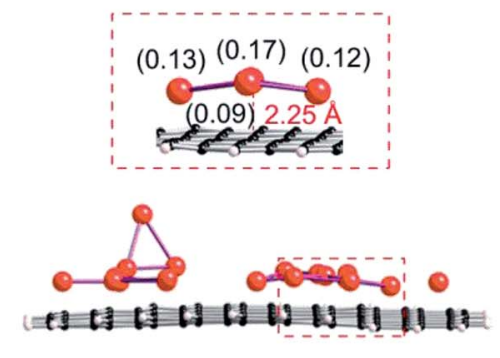
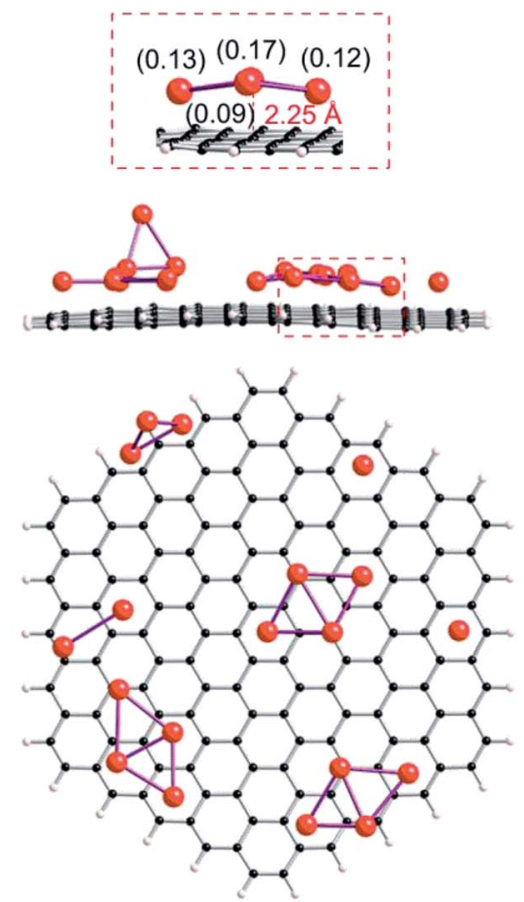

(iii) optimized geometry (Na case)
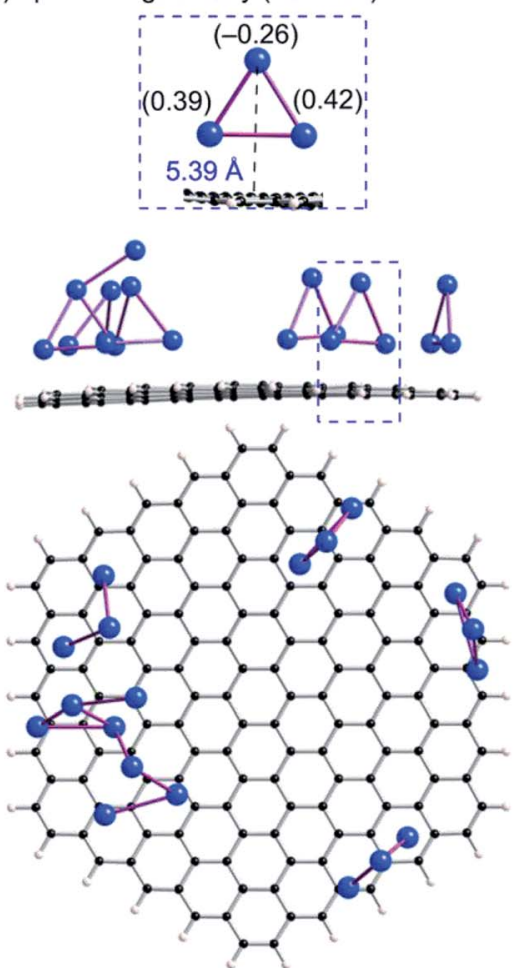

Fig. 11 Initial configuration of nineteen alkali atoms on a $\mathrm{C}_{150} \mathrm{H}_{30}$ plane (i) and its optimized geometry for lithium (ii) and sodium (iii). $\mathrm{Li}_{2}$ and $\mathrm{Li}_{4}$ clusters in (ii), and $\mathrm{Na}_{3}$ clusters in (iii) are formed on the plane.

results show the selective formation of triangle sodium clusters, independent of the number of sodium atoms on carbon surfaces. The large cluster formation is negligible, considering the restricted space of HCs that allows atoms to move freely. The DFT results are expected to be consistent with the ${ }^{23} \mathrm{Na}$ NMR results because the NMR measurements did not observe signals derived from metallic or quasi-metallic sodium clusters.

\subsection{Proposed storage model of lithium and sodium in HC}

It has been reported that $\mathrm{HC}$ prepared by heat treatment between 1000 and $1200{ }^{\circ} \mathrm{C}$ shows the largest capacity for lithium..$^{24,25}$ The reduction in Li capacity for HC heat-treated over $1300{ }^{\circ} \mathrm{C}$ has been explicated by the collapse of inner pores and shrinkage of the carbon structure, or blockage of the passage from surface to pores. However, the explanation is not applicable to the sodium storage because HC samples heated by HC-1600 showed the largest reversible capacity, as presented in Fig. 1. The average pore size of HC estimated using small angle $\mathrm{X}$-ray scattering grows larger with the increased heat treatment temperature of the carbon, ${ }^{43-45}$ although adsorption-desorption isotherm measurements show that nitrogen gas is not adsorbed to the pore. ${ }^{46}$ In the case of lithium storage in the pores of $\mathrm{HC}$ heat-treated at temperatures below $1300{ }^{\circ} \mathrm{C}$, lithium atoms disperse on the inner surface of the pores with the formation of $\mathrm{Li}_{2}, \mathrm{Li}_{4}$, or larger clusters along the wall, according to the model shown in Fig. 10 and 11 (Fig. 12). With increasing lithium storage, the pores are filled easily by lithium. Consequently, quasi-metallic large clusters are formed. In contrast, larger pores in $\mathrm{HC}$ heated over $1400{ }^{\circ} \mathrm{C}$ show a smaller inner surface area, which gives rise to less lithium storage. Furthermore, filling the larger pores with lithium is not stable because the electric potentials of such very large clusters are too close to that of lithium metal. Consequently, very few quasi-metallic lithium clusters in $\mathrm{HC}$ created by heat-treatment at temperatures higher than $1400{ }^{\circ} \mathrm{C}$ are observed using ${ }^{7} \mathrm{Li} \mathrm{NMR} .{ }^{20}$ (a)

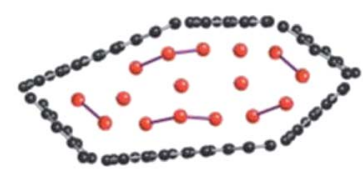

(c)

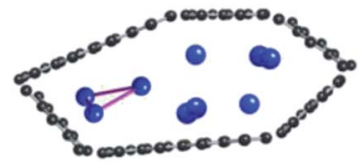

(b)

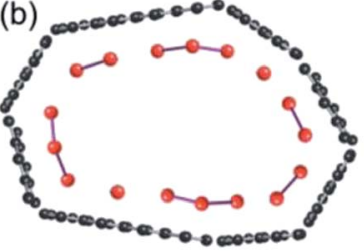

(d)

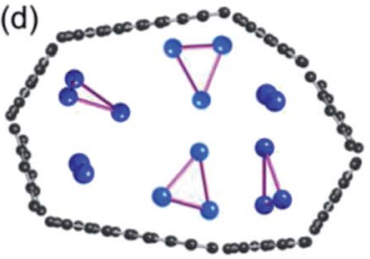

Fig. 12 Schematic models of lithium storage in pores of $\mathrm{HC}-1300$ (a) and HC-1600 (b), and sodium storage in HC-1300 (c) and HC-1600 (d). 
For sodium, the results suggest that the pore size in $\mathrm{HC}$ heated at temperatures below $1300{ }^{\circ} \mathrm{C}$ are too small to store many $\mathrm{Na}_{3}$ triangle clusters perpendicular to the pore surface (Fig. 12). The average size of the pores in the $\mathrm{HC}-1600$ is apparently the most preferable for accepting many $\mathrm{Na}_{3}$ clusters. However, the larger HOMO-LUMO gap of the triangle Na cluster prevents the exhibition of metallic properties. The sodium storage sites are thought to decrease in the $\mathrm{HC}$ heated at $2000{ }^{\circ} \mathrm{C}$, compared to HC-1600, which means that further shrinkage between carbon layers occurs. Additionally, carbonization at such a high temperature produces homogenization of carbon layers and reduces the defect structure. In our group's experiments, it can be observed that sodium storage capacity is controllable by the heat treatment conditions (temperature, treatment time, and so on) and the electrochemical conditions, including electrolyte additive and electrode binder/conductive additive. It should be considered that arranging sodium storage sites, not only of the void between carbon layers, but also of the space related to the defect structures, is important for the development of HC electrodes for high-capacity NIBs. We are observing details of the behaviour of the insertion of alkali metals into $\mathrm{HC}$, using electrochemical measurements and small angle X-ray scattering. Those results shall be published in later reports.

\section{Conclusions}

We conducted this ${ }^{23} \mathrm{Na}$ MAS NMR study, demonstrating that the peaks of the sodium components in HC-700, HC-900, HC1300, HC-1600, and HC-2000 tested in Na cells are ascribable to combinations of $\mathrm{Na}$ in electrolyte, reversible ionic Na components, irreversible $\mathrm{Na}$ components assigned to SEI or nonextractable sodium ions in $\mathrm{HC}$, and decomposed $\mathrm{Na}$ compounds. No quasi-metallic sodium component was observed. The experimentally obtained results were explained consistently by calculations of the stable structure of $\mathrm{Na}$ and $\mathrm{Li}$ on a graphene sheet. Although it is difficult to impart quasimetallic properties to the $\mathrm{Na}_{3}$ triangle clusters standing perpendicular to the pore surface, $\mathrm{Li}_{2}$ and $\mathrm{Li}_{4}$ clusters lying on the pore surface mutually interact more readily. Our model explains the assignment of ${ }^{23} \mathrm{Na}$ NMR peaks, and elucidates why the adequate heat-treatment temperature of $\mathrm{HC}$ (around $1600{ }^{\circ} \mathrm{C}$ ) for large sodium storage is higher than the heattreatment temperature for lithium storage. Results obtained using MQMAS NMR imply that the electrochemical capacity of sodium in HC is determined not only by the heat-treatment temperature, but also by the defect sites in the carbon structure, which correspond to hollow sites on graphene layers in HC. ${ }^{36}$

\section{Acknowledgements}

This work was supported by a JSPS Grant-in-Aid for Scientific Research (KAKENHI) No. 26870385. Authors thanks to Prof. Soshi Shiraishi (Gunma University) and Dr Taro Kinumoto (Oita University) for heat treatment of carbon samples at high temperature.

\section{Notes and references}

1 J. M. Tarascon and M. Armand, Nature, 2001, 414, 359.

2 D. Larcher and J. M. Tarascon, Nat. Chem., 2015, 7, 19.

3 N. Yabuuchi, K. Kubota, M. Dahbi and S. Komaba, Chem. Rev., 2014, 114, 11636.

4 S. Komaba, W. Murata, T. Ishikawa, N. Yabuuchi, T. Ozeki, T. Nakayama, A. Ogata, K. Gotoh and K. Fujiwara, Adv. Funct. Mater., 2011, 21, 3859.

5 K. Kubota and S. Komaba, J. Electrochem. Soc., 2015, 162, A2538.

6 M. S. Balogun, Y. Luo, W. Qiu, P. Liu and Y. Tong, Carbon, 2016, 98, 162.

7 V. Palomares, P. Serras, I. Villaluenga, K. B. Hueso, J. Carretero-González and T. Rojo, Energy Environ. Sci., 2012, 5, 5884.

8 M. D. Slater, D. Kim, E. Lee and C. S. Johnson, Adv. Funct. Mater., 2013, 23, 947.

9 M. Sawicki and L. L. Shaw, RSC Adv., 2015, 5, 53129.

10 K. Kubota, N. Yabuuchi, H. Yoshida, M. Dahbi and S. Komaba, MRS Bull., 2014, 39, 416.

11 R. J. Clément, P. G. Bruce and C. P. Grey, J. Electrochem. Soc., 2015, 162, A2589.

12 A. Ponrouch, A. R. Goñi and M. R. Palacín, Electrochem. Commun., 2013, 27, 85.

13 J. Zhao, L. Zhao, K. Chihara, S. Okada, J. Yamaki, S. Matsumoto, S. Kuze and K. Nakane, J. Power Sources, 2013, 244, 752 .

14 C. Bommier, W. Luo, W. Gao, A. Greaney, S. Ma and X. Ji, Carbon, 2014, 76, 165.

15 A. Fukunaga, T. Nohira, R. Hagiwara, K. Numata, E. Itani, S. Sakai, K. Nitta and S. Inazawa, J. Power Sources, 2014, 246, 387.

16 E. Irisarri, A. Ponrouch and M. R. Palacin, J. Electrochem. Soc., 2015, 162, A2476.

17 K. Gotoh, T. Ishikawa, S. Shimadzu, N. Yabuuchi, S. Komaba, K. Takeda, A. Goto, K. Deguchi, S. Ohki, K. Hashi, T. Shimizu and H. Ishida, J. Power Sources, 2013, 225, 137.

18 K. Gotoh, M. Maeda, A. Nagai, A. Goto, M. Tansho, K. Hashi, T. Shimizu and H. Ishida, J. Power Sources, 2006, 162, 1322.

19 K. Tatsumi, J. Conard, M. Nakahara, S. Menu, P. Lauginie, Y. Sawada and Z. Ogumi, Chem. Commun., 1997, 687.

20 J. Conard and P. Lauginie, Tanso, 2000, 191, 62.

21 K. Guérin, M. Ménétrier, A. Février-Bouvier, S. Flandrois, B. Simon and P. Biensan, Solid State Ionics, 2000, 127, 187.

22 M. Letellier, F. Chevallier, C. Clinard, E. Frackowiak, J. Rouzaud, F. Béguin, M. Morcrette and J. Tarascon, J. Chem. Phys., 2003, 118, 6038.

23 G. Hasegawa, K. Kanamori, N. Kannari, J. Ozaki, K. Nakanishi and T. Abe, ChemElectroChem, 2015, 2, 1917.

24 K. Tatsumi, T. Kawamura, S. Higuchi, T. Hosotubo, H. Nakajima and Y. Sawada, J. Power Sources, 1997, 68, 263. 25 J. R. Dahn, T. Zheng, Y. Liu and J. S. Xue, Science, 1995, 270, 590. 
26 V. Simone, A. Boulineau, A. de Geyer, D. Rouchon, L. Simonin and S. Martine, J. Energy Chem., 2016, DOI: 10.1016/j.jechem.2016.04.016, in press.

27 W. Xing, J. S. Xue and J. R. Dahn, J. Electrochem. Soc., 1996, 143, 3046.

28 S. Komaba, T. Ishikawa, N. Yabuuchi, W. Murata, A. Ito and Y. Ohsawa, ACS Appl. Mater. Interfaces, 2011, 3, 4165.

29 D. A. Stevens and J. R. Dahn, J. Electrochem. Soc., 2001, 148, A803.

30 D. A. Stevens and J. R. Dahn, J. Electrochem. Soc., 2000, 147, 1271.

31 D. Zhou, M. Peer, Z. Yang, V. G. Pol, F. D. Key, J. Jorne, H. C. Foley and C. S. Johnson, J. Mater. Chem. A, 2016, 4, 6271.

32 R. Alcántara, P. Lavela, G. F. Ortiz and J. L. Tirado, Electrochem. Solid-State Lett., 2005, 8, A222.

33 M. Nagao, C. Pitteloud, T. Kamiyama, T. Otomo, K. Itoh, T. Fukunaga, K. Tatsumi and R. Kanno, J. Electrochem. Soc., 2006, 153, A914.

34 H. Koller, G. Engelhardt, A. P. M. Kentgens and J. Sauer, J. Phys. Chem., 1994, 98, 1544.
35 D. C. Apperley, R. K. Harris and P. Hodgkinson, Solid State NMR: Basic Principles \& Practice, Momentum, New York, 2012.

36 P. Tsai, S. Chung, S. Lin and A. Yamada, J. Mater. Chem. A, 2015, 3, 9763.

37 D. Datta, J. Li and V. B. Shenoy, ACS Appl. Mater. Interfaces, 2014, 6, 1788.

38 Z. Xu, X. Lv, J. Li, J. Chen and Q. Liu, RSC Adv., 2016, 6, 25594.

39 G. Kaur, S. Gupta, P. Rani and K. Dharamvir, Phys. E, 2015, 74, 87.

40 M. S. Dresselhaus and G. Dresselhaus, Adv. Phys., 1981, 30, 139.

41 K. Nobuhara, H. Nakayama, M. Nose, S. Nakanishi and H. Iba, J. Power Sources, 2013, 243, 585.

42 W. Wan and H. Wang, Int. J. Electrochem. Sci., 2015, 10, 3177. 43 A. Gibaud, J. S. Xue and J. R. Dahn, Carbon, 1996, 34, 499.

44 K. Nishikawa, K. Fukuyama and T. Nishizawa, Jpn. J. Appl. Phys., Part 1, 1998, 37, 6486.

45 K. Fukuyama, T. Nishizawa and K. Nishikawa, Carbon, 2001, 39, 2017.

46 E. Buiel and J. R. Dahn, Electrochim. Acta, 1999, 45, 121. 